Preventive Care in Nursing and Midwifery Journal

2021; 11(3): 9-17

\title{
The Relationship between Coping Self-efficacy and Social Support with Psychological Well-being in Pregnant Women Referring to Health Centers During the Coronavirus Outbreak
}

\author{
$\underline{\text { Majid Yousefi Afrashteh }}^{1 *}$ (i) \\ ${ }^{* 1} \mathrm{PhD}$, Assistant Professor, Department of psychology, Faculty of humanities, University of Zanjan, Zanjan, Iran
}

*Corresponding Author Address: Department of psychology, Faculty of humanities, University of Zanjan, Zanjan, Iran

Tel: 0098-9187123796

Email: yousefi@znu.ac.ir

Received: 22 March $2021 \quad$ Accepted: 20 May 2021

\begin{abstract}
Background: Paying attention to the psychological health of pregnant women, especially during the critical time of the coronavirus outbreak, is a major global concern, especially in Iran.

Objectives: The aim of this study was to determine the relationship between coping self-efficacy and social support with the psychological well-being of pregnant women referring to health centers during the coronavirus outbreak.

Methods: This cross-sectional study was performed on 365 pregnant women aged 16-42 years referred to health centers in Hamadan in 2020. A demographic questionnaire, the short form of the Ryff psychological well-being scale, the Zimet multidimensional scale of perceived social support, and the coping self-efficacy scale developed by Chesney et al. were used to collect data. Data were analyzed using SPSS 26 statistical software.

Results: Our results showed that the problem-based (beta coefficient of 0.25), emotion-based (beta coefficient of 0.21), and social-based (beta coefficient of 0.19) coping styles had a significant role in pregnant women's psychological well-being at an error level of $<0.05$. Among the components of perceived social support, the family's (beta coefficient of 0.24) and others' (beta coefficient of 0.17) support rendered significant results. The regression of psychological well-being score with coping self-efficacy (beta coefficient of 0.25 ) and perceived social support (beta coefficient of 0.22 ) was statistically significant at an error level of $<0.05$.

Conclusion: Coping self-efficacy and perceived social support can affect the psychological well-being of pregnant women. So, abnormalities in these variables can lead to psychological problems in these individuals, which can be prevented by timely screening and providing counseling to the mother and her family, especially the spouse.
\end{abstract}

Keywords: psychological well-being, coping self-efficacy, social support, pregnancy

\section{Introduction}

The spread of infectious diseases, such as Covid19 , is associated with psychological distress and symptoms [1]. The implementation of health policies such as quarantine and preventive measures at national levels, despite positive consequences, has caused negative psychological complications in the society, including fear of the disease, fear of death, spreading false news and rumors, interfering with daily activities, travel bans and restrictions, reducing social communications with co-workers, friends, family members, occupational and financial problems, and several other consequences, that threaten the psychological health of people in the community [2-4]. Pregnant women and their fetuses are among high-risk groups during the epidemics of infectious diseases [5]. Pregnant women, due to a 
relatively weak immune system, are more prone to diseases [5-7]. Concerns about one's own and the fetus's health increase anxiety and decrease the psychological well-being of pregnant women. Statistics in the world and Iran also show that even under normal circumstances, women are twice as prone as men to develop depression [8]. Accordingly, there is a need to focus on the psychological health of pregnant women along with their physical health. Psychological wellbeing is one of the most important indicators of mental health [9] and is defined as the quality of life in terms of positive psychological performance [10]. This broad definition also encompasses the aspects of mental experiences and emotions, as well as cognitive assessments [11].

Coping self-efficacy is one of the parameters that can play an important role in people's psychological well-being and health [12-14]. Coping self-efficacy is an individual's selfconfidence or perceived self-efficacy in performing coping behaviors when encountered with life challenges and threats [15]. Selfefficacy, as a cognitive mediator, is affected by people's thoughts and feelings, decreasing in people with distress and anxiety [16]. Multiple studies have shown that individuals with higher self-efficacy more frequently engage in selfmanagement and self-care behaviors and react more appropriately facing health-threatening stressors. They can also control their negative emotions and have better health and lower levels of anxiety and depression [12, 17-19].

Social support is another variable contributing to psychological health in certain situations. Social support is defined as the amount of received love, companionship, and attention from family members, friends, and others [20]. Various studies have shown that social support has an important role in maintaining the health of individuals, especially pregnant women, and can be effective in reducing the negative consequences of environmental and social stressors and physical and psychological ailments [21-25].

Naderi et al., in a study on pregnant women, showed that social support was associated with psychological well-being [26]. The lack of social support and poor familial communications increase stress during pregnancy and lead to preterm delivery [27]. Another study reported a positive relationship between the self-efficacy of perceived social support and the psychological well-being of pregnant women [28]. A research by Gau et al. confirmed that low self-efficacy was associated with inability to tolerate labor and a greater fear of labor pain [29]. Also, Ginja et al. reported a positive relationship between social support and self-efficacy with the mental wellbeing of first-pregnant women [30].

According to the above-mentioned, it can be concluded that the critical condition caused by the Covid-19 pandemic has exposed pregnant women to serious psychological problems. Therefore, the main purpose of this study was to determine the relationships of coping self-efficacy and perceived social support with psychological wellbeing in pregnant women amid the Covid-19 outbreak.

\section{Methods}

The present research was a descriptive crosssectional study performed on pregnant women referring to health centers in Hamadan in 2020. In order to recruit the study sample according to Cochran's rule for research populations with an unknown size, 365 subjects were selected by the cluster randomization from two districts of Hamadan, enclosing 10 health centers (175 people from district 1 and 190 people from district 2). Inclusion criteria were the age of pregnancy more than three months, not experiencing any stressful event within the past three months, not taking psychiatric drugs, no history of acute psychiatric disorders (self-report), having the least education required for understanding the content of the questionnaire, and willingness to participate in the study. All the subjects were requested to sign a written informed consent, and they were assured about the confidentiality of their information.

After recruiting the subjects and collecting the data, statistical analysis was performed in SPSS 26 software. Data were reported as numbers and percentages. Also, the relationship of coping selfefficacy and perceived social support with psychological well-being was assessed using simultaneous multiple linear regression. The threshold of $\mathrm{P}<0.05$ was considered as the statistical significance level. The data was collected using several questionnaires, as described below.

Data Collection Instruments 
A demographic questionnaire was used to obtain information about the participants' demographic characteristics, including age, education, occupational status, number of pregnancies, number of children, and history of infertility.

The Zimet's perceived social support multidimensional scale, which was designed in 1988 by Zimet et al. [25], includes 12 questions and three subscales: friends (Q 6, 7, 9, and 12), family (Q 3, 4, 8, and 11), and important others (Q 1, 2, 5, and 10) [25]. The questionnaire is scored on a 7-point Likert scale from strongly disagree (score 1) to completely agree (score 7). A higher score indicates a perceived higher social support. The total score ranged from 4 to 28 for each subscale and from 12 to 84 for the whole scale. In a research by Ates et al., the reliability of this scale, as calculated based on the Cronbach's alpha internal consistency coefficient, was reported 0.89 for the whole scale and $0.87,0.84$, and 0.80 for the subscales of support by the family, friends, and important others, respectively [31]. Likewise, Shokri et al. approved the factor structure, validity, and reliability of the scale in Iran [32]. In the present study, the validity of the instrument based on the Cronbach's alpha method was obtained 0.761 .

The coping self-efficacy questionnaire was developed by Chesney et al. [12] and contains 26 questions organized in three subscales: 1- the cessation of unpleasant emotion and thoughts (12 items), 2- problem-based coping (10 items), and 3 - receiving support from the family and friends (4 items). The questionnaire is scored on a 3-point Likert scale, from "I cannot do it at all" (score 0), "I can somehow do it" (score 1 to 5), and "I can always do it" (score 5 to 10). The lowest and highest possible scores for each of the subscales were $0-120,0-90$, and $0-50$, respectively. A higher score reflected a stronger feeling of selfefficacy. Chesney et al. reported the Cronbach's alpha coefficients of $0.80,0.83$, and 0.91 for the subscales of the cessation of unpleasant emotion and thoughts, problem-based coping, receiving support from the family and friends, respectively [12]. In the study of Bahramian et al., the face and content validity of this scale was confirmed by the relevant professors, and its construct validity in the three subscales was confirmed using factor analysis [33]. In the present study, the Cronbach's alpha coefficient was obtained 0.749 .

Psychological well-being questionnaire (short form): The short form of the Ryff psychological well-being scale comprises 18 items and was developed by Ryff et al. [34]. This questionnaire measures the six main components of psychological well-being, including selfacceptance, environmental dominance, positive relationships with others, having a purposeful life, personal growth, and independence. The subject responds in a 6-point Likert scale and designates his/her agreement (strongly agree with score 6) or disagreement (strongly disagree with score 1) with each of the statements. A higher score indicates higher psychological well-being. This questionnaire has been developed for adults and also has a 54-phrase version. Ryff et al. to standardize the psychological well-being scale, performed the test on 321 individuals and reported the consistency coefficients of the subscales as 0.76 for autonomy, 0.90 for dominance, 0.87 for personal growth, 0.91 for positive relationships with others, 0.90 for purposeful life, and 930 for self-acceptance. The reliability of the subscales has been reported between 0.81 and 0.85 in a test-retest study on 117 subjects within a period of six weeks. In Iran, Seyed Tabaei et al. reported the Cronbach's alpha reliability coefficient of the whole scale as 0.71 , which is an acceptable value [35]. In the present study, the validity of the instrument was assessed based on the Cronbach's alpha method rendering a coefficient of 0.704. For data analysis, simultaneous multiple linear regression analysis was performed in SPSS 26 software.

\section{Results}

Out of 365 women participating in this study, $60 \%$ belonged to the age group of 20-30 years, and $39.7 \%$ aged 30 to 40 years. Overall, $66 \%$ of the participants were housewives, and $30 \%$ had academic education. The mean number of pregnancies was 1.90 , and the mean number of children was 1.70. Among the women studied, $8.2 \%$ had received treatments for infertility in the current pregnancy (Table 1). 
Table 1: Participants'Demographic Features

\begin{tabular}{|c|c|c|c|}
\hline \multicolumn{2}{|c|}{ Variables } & $\mathbf{N}$ & $\%$ \\
\hline \multirow{4}{*}{ Age (years) } & $16-20$ & 29 & 7.9 \\
\hline & $20-30$ & 186 & 60.0 \\
\hline & $30-40$ & 145 & 39.7 \\
\hline & $>40$ & 5 & 4.1 \\
\hline \multirow{2}{*}{ Education } & Academic & 110 & 30 \\
\hline & Non-academic & 255 & 70 \\
\hline \multirow{2}{*}{ Occupation } & Housewife & 240 & 66 \\
\hline & Employed & 125 & 34 \\
\hline \multirow{4}{*}{$\begin{array}{l}\text { Number of } \\
\text { pregnancies }\end{array}$} & 1 & 169 & 0.46 \\
\hline & 2 & 100 & 0.27 \\
\hline & 3 & 70 & 0.19 \\
\hline & 4 & 26 & 0.07 \\
\hline \multicolumn{2}{|c|}{ History of infertility } & 30 & 8.2 \\
\hline
\end{tabular}

Table 2 shows the mean and standard deviation for the studied variables. The last column displays the Pearson correlation coefficient reflecting the relationship of each variable with psychological well-being. The highest correlation was related to problem-based coping $(\mathrm{r}=0.35)$, and the lowest value was obtained for perceived social support $(\mathrm{r}=0.16)$.

The main statistical analysis of this study was multiple linear regression, the Enter mode. Before performing the analysis, its assumptions were tested. The assumption of the normality of the dependent variable was confirmed by the Kolmogorov-Smirnov test (statistic $=0.06$, $\mathrm{p}=0.07$ ). The assumption of the independence of errors was assessed by the Durbin-Watson test, which with an index of 1.89 supported the fulfillment of this assumption. The multiple linearity assumption was assessed for predictor variables based on the tolerance index, rendering indices higher than 0.60 , which indicated the fulfillment of multiple linearities.

Table 2: The Description of the Study Variables and the Pearson Correlation Coefficients Between Them

\begin{tabular}{ccccc}
\hline Variables & Items & Mean & SD & $\begin{array}{c}\text { Correlation with } \\
\text { well-being }\end{array}$ \\
\hline \multirow{3}{*}{ Coping self-efficacy } & $\begin{array}{c}\text { Problem-based } \\
\text { coping }\end{array}$ & 35.32 & 7.36 & $0.35^{* *}$ \\
\cline { 2 - 5 } & $\begin{array}{c}\text { Emotion-based } \\
\text { coping }\end{array}$ & 58.75 & 5.41 & $0.28^{* *}$ \\
\cline { 2 - 5 } & Social-based coping & 18.87 & 4.90 & $0.27^{* *}$ \\
\cline { 2 - 5 } $\begin{array}{c}\text { Perceived social } \\
\text { support }\end{array}$ & Total & 113.05 & 13.61 & $0.31^{* *}$ \\
\cline { 2 - 5 } & Friends & 21.08 & 6.17 & $0.16^{*}$ \\
\cline { 2 - 5 } & Family & 24.10 & 5.01 & $0.36^{* *}$ \\
\hline Psycortant others & 20.79 & 5.08 & $0.32^{* *}$ \\
\hline Psychological well-being & 65.97 & 13.42 & $0.32^{* *}$ \\
\hline
\end{tabular}

${ }^{*} \mathrm{P}<0.05 \quad{ }^{* * *} \mathrm{P}<0.01$

Table 3 shows the results of multiple linear regression analysis (the Enter mode) to investigate the relationship of different variables with psychological well-being. Problem-based coping with a beta coefficient of 0.25 , emotion-based coping with a beta coefficient of 0.21 , and social coping with a beta coefficient of 0.19 contributed significant roles in the psychological well-being of pregnant women $(\mathrm{P}<0.05)$. Among the components of perceived social support, family support with a beta coefficient of 0.24 and the support of important others with a beta coefficient of 0.17 delivered statistically significant results; however, the support of friends with a beta 
coefficient of 0.07 was statistically insignificant. The regression of the psychological well-being score with coping self-efficacy (with a beta coefficient of 0.25 ) and perceived social support (with a beta coefficient of 0.22) rendered significant results $(\mathrm{P}<0.05)$.

Table 3: The Results of Multiple Linear Regression

\begin{tabular}{ccccc}
\hline Variables & $\begin{array}{c}\text { Non-standard } \\
\text { Beta coefficient }\end{array}$ & $\begin{array}{c}\text { Standard Beta } \\
\text { coefficient }\end{array}$ & $\mathbf{t}$ & $\mathbf{P}$ \\
\hline $\begin{array}{c}\text { Problem-based } \\
\text { coping }\end{array}$ & 0.13 & 0.25 & 5.92 & 0.001 \\
\hline $\begin{array}{c}\text { Emotion-based } \\
\text { coping }\end{array}$ & 0.10 & 0.21 & 4.35 & 0.001 \\
\hline $\begin{array}{c}\text { Social-based } \\
\text { coping }\end{array}$ & 0.09 & 0.19 & 3.87 & 0.01 \\
\hline $\begin{array}{c}\text { Support from } \\
\text { friends }\end{array}$ & 0.01 & 0.07 & 1.71 & 0.08 \\
\hline $\begin{array}{c}\text { Support from } \\
\text { family }\end{array}$ & 0.12 & 0.24 & 5.22 & 0.001 \\
\hline $\begin{array}{c}\text { Support from } \\
\text { important others }\end{array}$ & 0.08 & 0.17 & 3.08 & 0.01 \\
\hline Regression based on the total score & & \\
\hline $\begin{array}{c}\text { Coping self- } \\
\text { efficacy }\end{array}$ & 0.12 & 0.25 & 5.72 & 0.001 \\
\hline $\begin{array}{c}\text { Perceived social } \\
\text { support }\end{array}$ & 0.10 & 0.22 & 4.67 & 0.001 \\
\hline
\end{tabular}

\section{$R^{2}=0.41$, adjusted $R^{2}=0.40, F=5.11$}

\section{Discussion}

With the spread of the novel coronavirus, human life has been affected in physical, psychological, and social dimensions. These impacts were even exaggerated by the implementation of quarantine regulations. This situation is much more problematic for certain groups of people, including pregnant women. In the present study, the psychological well-being of pregnant women was assessed from individual and social perspectives. The aim of this study was to investigate the relationship of coping self-efficacy and perceived social support with the psychological well-being of 365 pregnant women referred to health care centers of Hamadan (Iran) during the coronavirus outbreak. The mean psychological well-being score was obtained 61.27. Coping self-efficacy and perceived social support showed a positive and significant relationship with the psychological well-being of pregnant women. The $\mathrm{R}^{2}$ regression coefficient in this study was obtained at 0.41 . This value was reported to be 0.23 in the regression analysis conducted by Naderi et al., who studied the predicting relationship of psychological capitals and attachment styles with the psychological wellbeing of pregnant women [26]. One of the reasons for this difference may be related to the existence of the coping self-efficacy variable, which its great impact on psychological well-being was demonstrated in the present study. In fact, this variable contributed to an important part of the $\mathrm{R}^{2}$. Another important point is the time of data collection, which coincided with the novel coronavirus outbreak in Iran. In critical circumstances, the relationship of well-being with perceived social support and coping self-efficacy is augmented. In other words, the psychological well-being of pregnant women is more entangled with social support and coping self-efficacy under critical than normal conditions.

The results of the present study showed that family support, support from important others, and the total score of social support were significant predictors of psychological well-being. This finding was in line with the results of a study by Paula et al. who found a significant relationship between perceived social support and psychological well-being in adults [17]. Ginja et al. also reported a significant relationship between 
perceived social support and psychological wellbeing in mothers with the first pregnancies [30]. Moreover, Goudarz et al. reported a significant relationship between social support and psychological well-being among the elderly [36]. The results of the aforementioned studies were in line with our findings. To explain these observations, it can be said that perceived social support has a positive relationship with positive emotions and life satisfaction while it is negatively associated with depression, anxiety, and stress [37,38]. The main sources of perceived social support (i.e., family members and friends) role as the psychological resources for people who can help them to withstand and cope with stressful situations. Social support affects the psychological factors and viewpoints through which people perceive themselves and the world around them and improves their psychological well-being. Social support acts as a shield against the damages and challenges that people underestimate. In pregnant women, high levels of perceived social support are essential to enhance their psychological and emotional well-being [38]. During pregnancy, women experience depression and dissatisfaction, and this affects the capability of their immune system to fight against diseases. On the other hand, high levels of social support, in which family support plays an important role, increase the quality of life and life-expectancy and augment the immune system [39]. Social support can improve psychological well-being both directly, when the individual feels himself/herself in a large social network, and indirectly through playing the role of a shield against stressful events and emotional reactions [40].

Our results showed that coping self-efficacy and its components had a significant role in predicting psychological well-being. This finding was consistent with the findings of Mazaheri and Bahramian [19] and Laureano et al. [41], who reported a significant relationship between coping self-efficacy and psychological well-being. Likewise, Caprara and Steca reported a positive relationship between coping self-efficacy and happiness [18]. In explanation, it is noteworthy to say that people with high self-efficacy usually have a better understanding of their psychological characteristics, communicate with others easier, can readily control negative emotions, all of which finally culminate in higher life satisfaction. According to Chesney et al. [12], the perception of humans from self-efficacy has a significant impact on their way of thinking, motivations, behaviors, and performance when they face challenges and life threats. In fact, human behavior in situations where he is confident in his ability is different from the situations where there is a sense of insecurity and incompetency. Also, a strong feeling of self-efficacy boosts one's personal health and capability to perform tasks in various ways and causes people to consider difficult situations as the challenges that they must conquer. In fact, they are assured that they can control potential threats and adapt well to the situation to experience less anxiety and depression and higher psychological well-being [42].

Various factors such as changes in sexual performance, unwanted pregnancy, infertility, sleep disorders, changes in body image, economic status, religious beliefs, ill family members, and the spouse's psychological health may affect the psychological well-being of pregnant women during pregnancy. However, these items were not assessed in this study. Therefore, it is recommended to address these parameters in future studies. On the other hand, this study was conducted in the cultural context of Hamedan, so it may not be generalizable to other geographic areas and social groups.

\section{Conclusion}

In the present study, a significant relationship was observed between the studied variables and the psychological well-being of pregnant women during pregnancy. In this regard, individuals with higher coping self-efficacy (problem-, emotion-, and social-based coping) and perceived social support (from the family and important others) were more likely to experience higher levels of psychological well-being during pregnancy. Regarding the importance of the subject and the existence of various determinants such as different cultural contexts and psychological issues during pregnancy, it is recommended to conduct similar studies in different populations. Also, health experts and counselors are recommended to trigger or augment social support and coping self-efficacy in pregnant women. 


\section{Acknowledgments}

The project's protocol was approved under the code of 58278 in the Department of Psychology of Zanjan University. We thank the Vice Chancellor for Research of Zanjan University for its support and also all the experts of health centers who helped the researcher in identifying and recruiting the participants. We sincerely appreciate the women participating in the research.

\section{Conflict of interest}

The authors declare that there is no conflict of interest.

\section{Funding:}

This research has been done with the personal fund of researchers.

\section{References}

1.Bao Y, Sun Y, Meng S, Shi J, Lu L. 2019-nCoV epidemic: address mental health care to empower society. Lancet. 2020; 395(10224): e37-38.

2.Barbisch D, Koenig KL, Shih FY. Is there a case for quarantine? Perspectives from SARS to Ebola. Disaster Med Public Health Prep. 2015; 9(5): 547-53.

3.Brooks SK, Webster RK, Smith LE, Woodland $\mathrm{L}$, Wessely $\mathrm{S}$, Greenberg $\mathrm{N}$, et al. The psychological impact of quarantine and how to reduce it: rapid review of the evidence. lancet. 2020; 395(10227): 912-20.

4.Duan L, Zhu G. Psychological interventions for people affected by the COVID-19 epidemic. Lancet Psychiatry. 2020; 7(4): 300-2.

5.Chen H, Guo J, Wang C, Luo F, Yu X, Zhang $\mathrm{W}$, et al. Clinical characteristics and intrauterine vertical transmission potential of COVID-19 infection in nine pregnant women: a retrospective review of medical records. lancet. 2020; 395(10226): 809-15.

6. Yu N, Li W, Kang Q, Xiong Z, Wang S, Lin X, et al. Clinical features and obstetric and neonatal outcomes of pregnant patients with COVID-19 in Wuhan, China: a retrospective, single-centre, descriptive study. Lancet Infect Dis. 2020; 20(5): 559-64.

7.Liu H, Wang LL, Zhao SJ, Kwak-Kim J, Mor $\mathrm{G}$, Liao AH. Why are pregnant women susceptible to COVID-19? An immunological viewpoint. J Reprod Immunol. 2020; 139: 103122.

8. Yavari P, Akbarin H, Sharifi H. Epidemiology textbook of Prevalent Disease in Iran. Tehran: Gap; 2019: 535. [In Persian]

9. Ryff CD, Keyes CL. The structure of psychological well-being revisited. $\mathrm{J}$ pers soc psychol. 1995; 69(4): 719.

10. Huta V, Waterman AS. Eudaimonia and its distinction from hedonia: Developing a classification and terminology for understanding conceptual and operational definitions. Journal of Happiness Studies. 2014 Dec; 15(6):1425-56.

11. Kim HS, Plester BA. Harmony and distress: humor, culture, and psychological well-being in south Korean organizations. Front psychol. 2019; 9: 2643.

12. Chesney MA, Neilands TB, Chambers DB, Taylor JM, Folkman S. A validity and reliability study of the coping self-efficacy scale. $\mathrm{Br} \mathrm{J}$ Health Psychol. 2006; 11(3): 421-37.

13. Pisanti R, Lombardo C, Lucidi F, Lazzari D, Bertini M. Development and validation of a brief occupational coping self-efficacy questionnaire for nurses. J Adv Nurs. 2008; 62(2): 238-47.

14. January J. (2010). Hope and coping selfefficacy as predictors of psychological well-being among adolescents in Gauteng. [Unpublished dissertation]. South Africa: University of Johanesburg.

15. Cunningham CA, Cramer RJ, Cacace S, Franks M, Desmarais SL. The Coping SelfEfficacy Scale: Psychometric properties in an outpatient sample of active duty military personnel. Mil Psychol. 2020; 32(3): 261-72.

16. Shahdadi H, Mansuri A, Khammari M, Ghorbani-Dindarlu F. An Investigation of the Relationship between mental health and SelfEfficacy in Diabetic Patients Referring to Ali Asghar Clinic of Zahedan. J Diabetes Nurs. 2016; 4(1): 85-94. [In Persian]

17. de Paula Couto MC, Koller SH, Novo R. Stressful life events and psychological well-being in a Brazilian sample of older persons: The role of resilience. Ageing Int. 2011; 36(4): 492-505.

18. Caprara GV, Steca P. Affective and social self-regulatory efficacy beliefs as determinants of positive thinking and happiness. European psychol. 2005; 10(4): 275-86.

19. Mazaheri M, Bahramian S. Prediction of Psychological Well-Being based on the Positive 
and Negative Affection and Coping Self-Efficacy. J Posit Psychol Res. 1(4): 1-14.

20. Sarafino EP, Smith TW. Health psychology: Biopsychosocial interactions. John Wiley \& Sons; 2014 Jan 13.

21. Naderi-Boldaji R, Moradi A, Mobasheri M, mirzaeian R, Yusefi Z. Exploring the relationship between the social support and attachment styles for predict psychological well-being of Pregnant Women In Borujen County. J Clin Nurs Midwifery. 2014; 2(4) :37-44. [In Persian]

22. Barjasteh S, Moghaddam Tabrizi F. Antenatal anxiety and pregnancy worries in association with marital and social support. Nurs Midwifery J. 2016; 14(6): 504-15. [In Persian]

23. Abdollahzade Rafi $M$, Hassanzadeh $M$, Ahmadi S, taheri M, Hosseini M. Relationship between social support with depression and anxiety during third trimester pregnancy. Iran $\mathbf{J}$ Nurs Res. 2012; 7(26): 1-10. [In Persian]

24. Adamczyk K, Segrin, Ch. Perceived social support and mental health among single vs. partnered Polish young adults. Curr Psychol. 2015; 34(1): 82-96.

25. Zimet GD, Dahlem NW, Zimet SG, Farley GK. The multidimensional scale of perceived social support. J Pers Assess. 1988; 52(1): 30-41.

26. Naderi -Boldaji R, Moradi A, Mobasheri M, mirzaeian R, Yusefi Z. Exploring the relationship between the social support and attachment styles for predict psychological well-being of pregnant women in Borujen county. J Clin Nurs Midwifery. 2014; 2(4) :37-44. [In Persian]

27. Basharpoor S, Heydarirad H, Daryadel SJ, Heydari F, Ghamari Givi H, Kishore J. The role of perceived stress and social support among predicting anxiety in pregnant women. J Holist Nurs Midwifery. 2017; 27(2): 9-16. [In Persian]

28. Yuksel A, Bayrakci H. Self-efficacy, psychological well-being and perceived social support levels in pregnant women. Int J Car Sci. 2019; 12(2): 1120.

29. Gau ML, Chang CY, Tian SH, Lin KC. Effects of birth ball exercise on pain and selfefficacy during childbirth: a randomised controlled trial in Taiwan. Midwifery. 2011; 27(6): e293-300.

30. Ginja S, Coad J, Bailey E, Kendall S, Goodenough T, Nightingale S, et al. Associations between social support, mental wellbeing, selfefficacy and technology use in first-time antenatal women: data from the BaBBLeS cohort study. BMC Pregnancy Childbirth. 2018; 18(1): 1-1.

31. Ates B. Perceived Social Support and Assertiveness as a Predictor of Candidates Psychological Counselors' Psychological WellBeing. Int Educ Stud. 2016; 9: 28-39.

32. Shokri O, Kormi Nouri R, Farahani $M$, Moradi A. The Quality of College Life from Viewpoint of Native and Non-Native Students of Tehran's Public Universities. J Iran Cultur Res. 2016; 9(2): 75-100. [In Persian]

33. Bahramian H, Morovati Z, Yousefi Afrashteh, M, amiri, M. Reliability, validity, and factorial analysis of coping self-efficacy scale. Clin Psychol Pers. 2017; 15(2): 215-26.

34. RYFF, Carol D.; KEYES, Corey LM; HUGHES, Diane L. Status inequalities, perceived discrimination, and eudaimonic well-being: Do the challenges of minority life hone purpose and growth?. Journal of health and Social Behavior, 2003, 275-291.

35. Seyed Tabaee R, Rahmatinejad P, Mohammadi D, Etemad A. The role of coping strategies and cognitive emotion regulation in well-being of patients with cancer. J. Inflamm Dis. 2017; 21(2): 41-49. [In Persian]

36. Goudarz M, Foroughan M, Makarem A, Rashedi V. Relationship between social support and subjective well-being in older adults. Iran $\mathbf{J}$ Age. 2015; 10(3): 110-19. [In Persian]

37. Klainin-Yobas P, Ramirez D, Fernandez Z, Sarmiento J, Thanoi $\mathrm{W}$, Ignacio $J$, et al. examining the predicting effect of mindfulness on psychological well-being among undergraduate students: A structural equation modelling approach. Pers individ differ. 2016, 91: 63-68.

38. Halbreich U, Karkun S. Cross-cultural and social diversity of prevalence of postpartum depression and depressive symptoms. J Affect Disord. 2006; 91: 97-111.

39. Fisher J, de Mello MC, Patel V, Rahman A, Tran T, Holton S, et al. Prevalence and determinants of common perinatal mental disorders in women in low- and lower-middleincome countries: a systematic review. Bull World Health Organ. 2012; 90(2): 139-49.

40. Cohen S, Wills TA. Stress, social support, and the buffering hypothesis. Psychol Bull. 1985; 98: 310-57.

41. Laureano C, Grobbelaar HW, Nienaber AW. Facilitating the coping self-efficacy and 
psychological well-being of student rugby players. S Afr J Psychol. 2014; 44(4): 483-97.

42. Thom B, Benedict C. The impact of financial toxicity on psychological well-being, coping selfefficacy, and cost-coping behaviors in young adults with cancer. J adolesc Young Adult Oncol. 2019. 8(3): 236-42. 